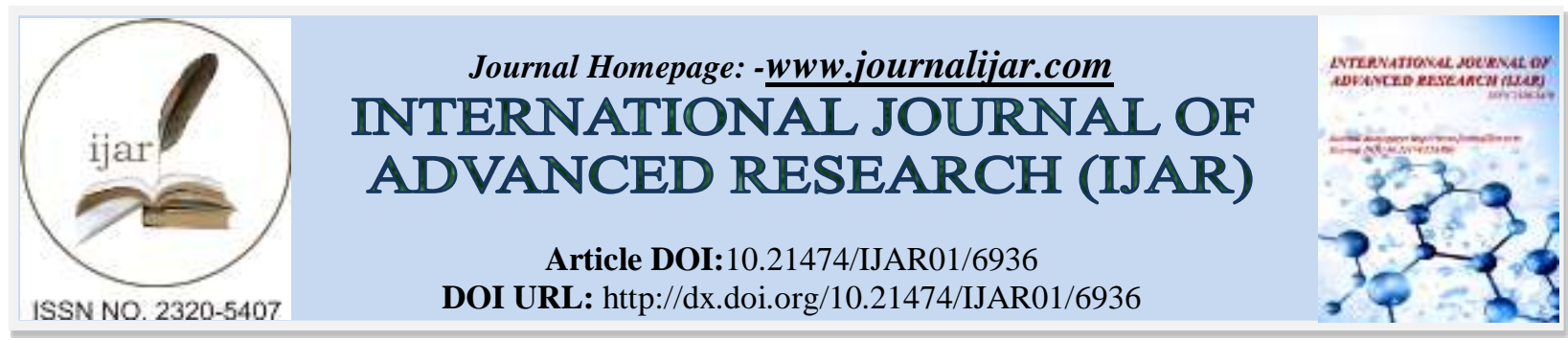

RESEARCH ARTICLE

\title{
QUINOLONE RESISTANT ESCHERICHIA COLI ISOLATED FROM CHICKEN MEAT IN BOSNIA AND HERZEGOVINA.
}

\section{Vildana Hadzic ${ }^{1}$ and Anesa Jerkovic Mujkic ${ }^{2}$.}

1. Hospital for Respiratory diseases and TBC, 72270 Travnik, Bosnia and Herzegovina.

2. Faculty of Science, University of Sarajevo, 71000 Sarajevo, Bosnia and Herzegovina.

\section{Manuscript Info}

Manuscript History

Received: 13 February 2018

Final Accepted: 15 March 2018

Published: April 2018

Keywords:-

Nalidixic acid, Ciprofloxacin, A ntimicrobial agents, Veterinary medicine.

\begin{abstract}
Fluoroquinolones are broad-spectrum antimicrobial agents that are highly effective for the treatment of a variety of infections in humans and animals. Resistance to fluoroquinolones develops more rapidly in E. coli than in other members of the Enterobacteriaceae . Retail poultry products are routinely heavily contaminated with avian fecal E. coli. Such E. coli, which can be antibiotic resistant (including to FQs), widely contaminates kitchen surfaces during meal preparation, is not readily removed from these surfaces by standard cleaning procedures, and can subsequently be isolated from the feces of persons preparing the meals. The study included 55 chicken meat samples collected randomly from retail supermarkets, butcheries and slaughterhouses. Susceptibility tests were performed using the Kirby-Bauer method on Mueller-Hinton agar inaccordance with Clinical and Laboratory Standards Institute, 2017 and using Ampicillin $(10 \mu \mathrm{g})$, Amoxicililn $(25 \mu \mathrm{g})$, Ciprofloxacin $(5 \mu \mathrm{g})$ and Nalidixic acid discs $(30 \mu \mathrm{g})$. The zones of inhibition was measured, recorded, and interpreted according to the recommendation of the CLSI. Resistance to fluoroquinolone agents Ciprofloxacin was demonstrated in $95 \%$ of the E. coli isolates. Resistance to antibiotics from the group of aminopenicillins, betalactam antibiotics that act on the synthesis of the bacterial cell wall was also established in most of the tested samples. Out of $40 \mathrm{E}$. coli isolates, $36(90 \%)$ were restistant to amoxicillin and ampicillin. Amoxicillin resistant isolates were found in 36 of 40 chicken meat samples.
\end{abstract}

Copy Right, IJAR, 2018,. All rights reserved.

\section{Introduction:-}

Escherichia coli is the most prevalent facultative anaerobic species in the gastrointestinal tract of human and animals, usually a harmless microbe, but it is also a medically important bacteria causing a number of significant illnesses (Friedman et al., 2002). Animals can also become infected from water or food, contaminated with wastes of human or animal origin or with human carrier workers. One of the possible ways of entry of various microbes could be the handling of meat and meat products by adopting improper hygienic measures during handling and processing (Kiranmayi et al., 2011). The use of antimicrobial agents to treat disease in food-producing animals started in the mid-1940s. The introduction of antimicrobial agents in commercial feed for cattle, pigs, and poultry started in the early 1950s. Soon after this, scientists began studying the possible effects of long-term use of 
antimicrobial agents (Amundsen et al., 1988). In Europe, concern for the spread of antimicrobial-resistant bacteria from the large reservoirs in food animals led the countries in the European Union to abandon the use of antimicrobial agents for growth promotion in food animals by January $1^{\text {st }} 2006$ (Anderson et al., 2003). Although withdrawal of antimicrobial agents for growth promotion may significantly reduce the total amount of antimicrobial agents used in animals, available data indicate that the consumption of antimicrobial agents for clinical therapy in animals is considerable and may even exceed the consumption in humans (Arathy et al., 2011). Most of the antimicrobial agents used for growth promotion in animals are mainly active against gram-positive bacteria, whereas many of the antimicrobial agents used in veterinary clinical therapy are broad spectrum and are mainly active against gram-negative bacteria, such as Salmonella and E. coli.

Fluoroquinolones are broad-spectrum antimicrobial agents that are highly effective for the treatment of a variety of infections in humans and animals. The use of fluoroquinolone (FQ) agents in food animal production is suspected of selecting for FQ-resistant gram-negative bacteria, such as Salmonella enterica, Campylobacter jejuni, and Escherichia coli, that can be transmitted to humans via the food supply (Garau et al., 1999; Gorbach, 2001; Smith et al., 1999, Chiu et al., 2002). The past two decades have witnessed major increases in emergence and spread of multidrug-resistant bacteria and increasing resistance to newer compounds, such as fluoroquinolones and certain cephalosporins (Levy \& Marshall, 2004). Resistance to fluoroquinolones develops more rapidly in E. coli than in other members of the Enterobacteriaceae (Gales et al., 2000). Retail poultry products are routinely heavily contaminated with avian fecal E. coli (Gorbach, 2001; Smith et al., 1999). Such E. coli, which can be antibiotic resistant (including to FQs) (Chiu et al., 2002), widely contaminates kitchen surfaces during meal preparation, is not readily removed from these surfaces by standard cleaning procedures, and can subsequently be isolated from the feces of persons preparing the meals (Cogan et al., 1999; Linton et al., 1977). Thus, the possibility of foodborne transmission of FQ-resistant E. coli from poultry to humans is highly plausible. Studies of farms have shown an association of multidrug-resistant E. coli with chronic antimicrobial drug exposure (McEwen \& Fedorka-Cray, 2002; Jensen et al., 2006), there are few data on temporal trends of antimicrobial drug resistance in food animal $E$. coli isolates, particularly those recovered before 1980 . The aim of the study is to evaluate the fluoroquinolone resistance of $E$. coli isolated from the chicken meat in Bosnia and Herzegovina.

\section{Materials and Methods:-}

The study included 55 chicken meat samples collected randomly from retail supermarkets, butcheries and slaughterhouses. Meat samples were aseptically collected and then packaged in sterile polythene zip bags and carried to the laboratory in aseptic conditions in a cold box within two hours from the time of purchase. Duplicate samples were obtained whenever possible. All samples were analyzed within 2-4 hours after their arrival to the laboratory. A sharp sterile knife was used to cut sample from surface in sterile tray. To isolate bacteria, a $25 \mathrm{-g}$ portion of sample was placed into sterile $225 \mathrm{ml}$ buffered peptone water. For the preparation of samples, we used the guidelines given in the Microbiology of Food and Feeding Standards - Preparation of test samples, initial suspensions and decimal dilutions for microbiological tests (EN ISO 6887-1: 1999, IDT, ISO 6887-1: 1999, IDT). The time between the end of the preparation of the initial suspension and the point when the inoculum is in contact with the nutrient medium should not be more than 45 minutes, while the time between preparation of the initial suspension and the beginning of the preparation of decimal dilutions is limited to 30 minutes.

After the preparation of the samples, the microbiological analysis was carried out according to the ISO standard Microbiology of food and animal feedingstuffs - Horizontal method for counting < beta> glucuronidase positive Escherichia coli - Part 2: Colony counting technique at $44{ }^{\circ} \mathrm{C}$ using 5-bromo-4-chloro -3-indolyl-beta] -Dglucuronide (ISO 16649-2: 2001, IDT). Volume of $1 \mathrm{ml}$ of the initial solution is aseptically transferred by micropipette to a sterile Petri dish. Two plates were inoculated after dilution. The procedure is repeated with other decimal dilutions, using new sterile pipettes for each dilution. In each Petri dish, $15 \mathrm{ml}$ of TBX medium was poured, which was previously cooled to $44-47^{\circ} \mathrm{C}$ in a water bath. The inoculum was carefully mixed with the medium and left to harden on the horizontal surface. The time that flows between the distribution of the inoculum in the vessel and the spillage of the media should not exceed 15 minutes.

After incubation for $24 \mathrm{~h}$, all Petri plates were examined for the rise of Escherichia coli colonies. The ATCC strain of E. coli 25922 was used as a control strain. All the bacteriological media and antimicrobial disks were purchased from HiMedia Laboratories, Mumbai, India. Susceptibility tests were performed using the Kirby-Bauer method on Mueller-Hinton agar in accordance with Clinical and Laboratory Standards Institute, 2017 (CLSI, 2017) and using ampicillin $(10 \mu \mathrm{g})$, amoxicililn $(25 \mu \mathrm{g})$, ciprofloxacin $(5 \mu \mathrm{g})$ and nalidixic acid discs $(30 \mu \mathrm{g})$ (Mast group, UK). The 
E. coli isolates were inoculated in nutrient broth and incubated at $35+2{ }^{\circ} \mathrm{C}$ for $24 \mathrm{~h}$. The broth was diluted in normal saline solution to a density of $0.5 \mathrm{McF}$ arland turbidity standard. Cotton swabs were used for streaking the diluted broth onto Mueller-Hinton agar plates. After 15 minutes, antibiotic discs were placed $30 \mathrm{~mm}$ apart and $10 \mathrm{~mm}$ away from the edge of the plate. Plates were inverted and incubated aerobically at $35+2{ }^{\circ} \mathrm{C}$ for 16 to 18 hours. The zones of inhibition was measured, recorded, and interpreted according to the recommendation of the CLSI [CLSI, 2017].

\section{Results:-}

Out of 55 tested chicken meat samples, E. coli was isolated from 40 (72.73\%) samples (Table 1). E. coli was recovered from 21 frozen and 19 fresh chicken meat samples.

Table. 1:-Origin of $E$. coli isolates

\begin{tabular}{|c|c|c|c|c|}
\hline Chicken meat & Skin & Leg & Liver with heart & $\begin{array}{c}\text { Mechanically } \\
\text { separated meat }\end{array}$ \\
\hline Frozen & 8 & 4 & 2 & 7 \\
\hline Raw & 8 & 5 & 2 & 4 \\
\hline Total & 16 & 9 & 4 & 11 \\
\hline
\end{tabular}

The resistance rates for each tested antibiotic for 40 isolates are given in Graph 1. Occurrence of resistance among E. coli isolates from chicken meat for all antimicrobiotics was extremely high. Of the antimicrobiotics included, the highest rates of resistance were found for quinolones. Resistance to nalidixic acid was determined by $100 \%$ of the tested chicken samples Total resistance is the absence of the inhibition zone around the nalidixic acid disc was recorded for 38 tested samples. An inhibition zones were detected only for two isolates: one isolate from mechanically seperated chicken meat $(12 \mathrm{~mm})$ and one isolate from frozen chicken drumstick $(4 \mathrm{~mm})$.

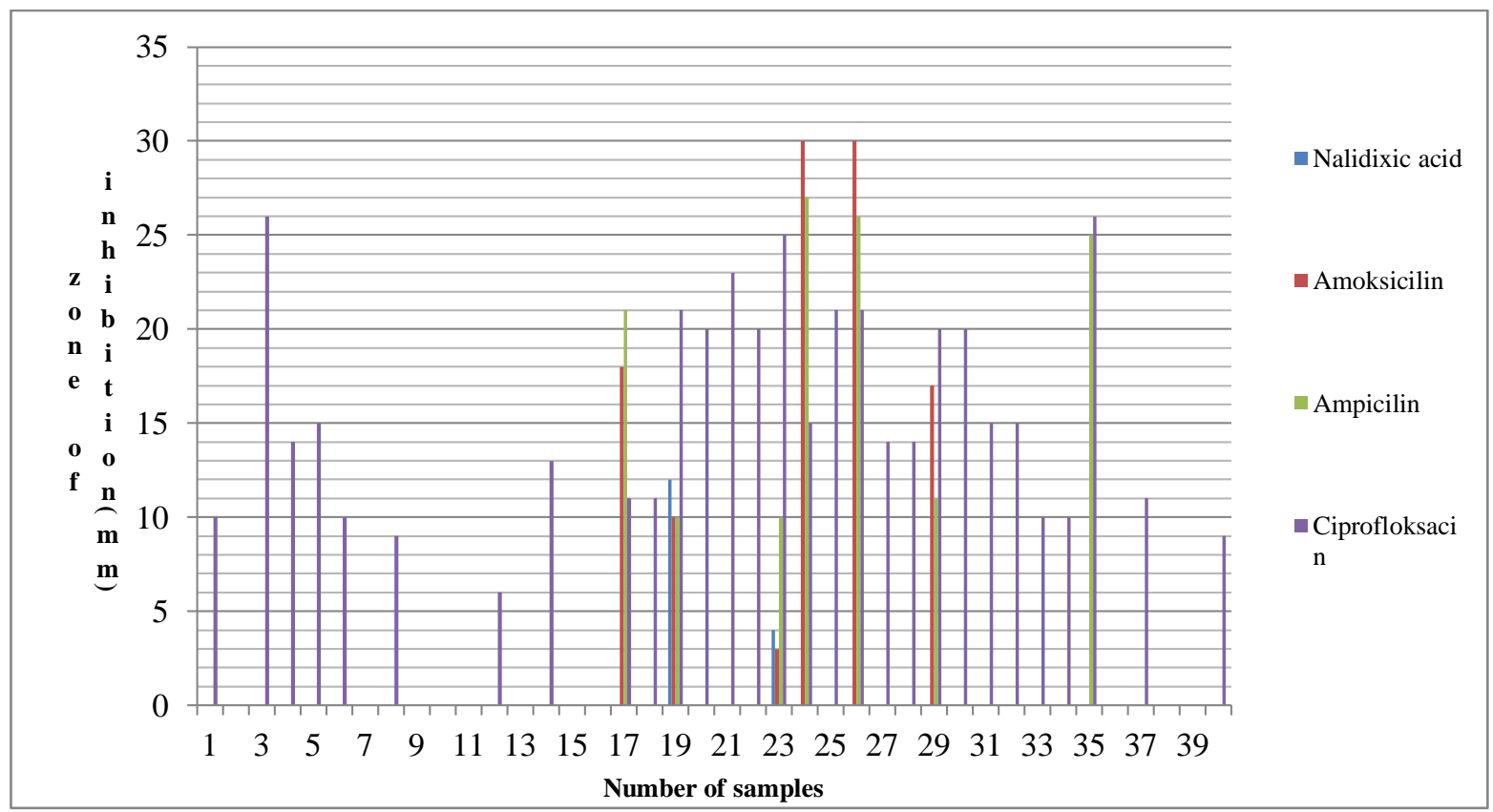

Graph 1:- Graphical presentation of resistant isolates of Escherichia coli from chicken meat samples

Resistance to fluoroquinolone agents ciprofloxacin was demonstrated in $95 \%$ of the E. coli isolates. Isolate from a sample of chicken drumstick showed sensitivity to the tested antibiotic with an inhibition zone of $25 \mathrm{~mm}$. Also, isolate from a sample of mechanically eliminated chicken meat showed sensitivity to the antibiotic tested, and the measured inhibition zone was $26 \mathrm{~mm}$. Resistance to antibiotics from the group of aminopenicillins, beta-lactam antibiotics that act on the synthesis of the bacterial cell wall was also established in most of the tested samples. Out of 40 E. coli isolates, 36 (90\%) were restistant to amoxicillin and ampicillin. Amoxicillin resistant isolates were found in 36 of 40 chicken meat samples. More precisely, tree samples: showed sensitivity to both antimicrobials, 
while one sample of mechanically separated meat were only sensitive to amoxicillin and one sample of mechanically separated meat was only sensitive to ampicillin.

\section{Discussion:-}

Antimicrobial resistance has been recognized as an emerging worldwide problem in human and veterinary medicine (Kiranmayi et al., 2011; Jensen et al., 2006) both in developed and developing countries. According to EFSA (European Food Safety Authority) and ECDC (European Centre for Disease Prevention and Control), commensal $E$. coli is typically chosen as the representative indicator of antimicrobial resistance in gram-negative bacteria, as it is commonly present in animal faeces, may be relevant to human medicine and can often acquire conjugative plasmids, which can carry resistance determinants and are transferable between enteric bacteria [EFSA \& ECDC, 2018]. Since 2014., EU legislation has mandated the monitoring of antimicrobial resistance in indicator E. coli from food-producing animals and their food products. Fluoroquinolones belong to an important class of antimicrobials against infections caused by gram-negative bacteria with excellent activities against E. coli (Blanco, et al., 1997; McDonald et al., 2001)

E. coli that are resistant to quinolones and fluoroquinolones contaminate many retail meat products, particularly poultry, corresponding with the use of fluoroquinolones in food animals, particularly chickens and turkeys (Johnson et al., 2003).

In the present study all of the $E$. coli isolated from chicken meat (100\%) were resistant to nalidixic acid (quinolone) and $92.5 \%$ were resistant to ciprofloxacin (fluoroquinolone). Rate of resistance to aminopenicillines (amoxicillin and ampicillin) was also extremely high. For amoxicillin and ampicillin the resistance levels were identical (90\%). Similar findings were reported for nalidixic-resistance for E. coli isolates recovered from chickens in Iran (Moniri \& Dastehgoli, 2005), where $100 \%$ isolates were resistant to nalidixic acid, but a lower percentage of resistance $(41.9 \%)$ was found for ciprofloxacin. Extremely high resistance to ciprofloxacin was found in Bogota (Colombia). All of $182 \mathrm{E}$. coli strains obtained from chicken feces and retail poultry meat were resistant to ciprofloxacin (Arias et al., 2005). The rates of resistance found for tested antimicrobials in E. coli isolates obtained from the chicken meat in Bosnia and Herzegovina tend to be higher than the levels reported in European Union countries. In EU during 2016, quinolone resistance was the most common trait and occurrence was overall very high in indicator $E$. coli from broilers and their meat at $59.8 \%$ and $64.0 \%$ for nalidixic acid and ciprofloxacin, respectively and rate of resistance to ampicillin was also very high (58.0\%) in the EU member states (EFSA \& ECDC, 2018). We can agree with the opinion of Reis and Santos (Reis et al., 2016) that prophylactic use of quinolones has a significant role in the increasing emergence of bacteria resistant to these antimicrobials. Molecular-epidemiological studies [Johnson et al., 2006; Thorsteinsdottir et al., 2010), showed that human and chicken fluoroquinolone-resistant E. coli isolates were closely related, demonstrating that poultry and their food products can be a source of resistant in humans. To our knowledge, seven countries do not use fluoroquinonlones in poultry: Australia, Denmark, Finland, Iceland, Norway, Sweden and the United States. All of these countries have, by international standards, low levels of fluoroquinolone resistance in human Campylobacter infection. In contrast, during 2016 (EFSA \& ECDC, 2018), extremely high proportions of human isolates resistant to ciprofloxacin were observed in several countries, most noticeably in Portugal (94.0\%), Estonia (91.2\%), Lithuania (86.9\%), Cyprus (86.8\%), Italy (85.0\%) and Spain $(84.5 \%)$. The extremely high recovery rate of (fluoro)quinolone-resistant E. coli from broiler meat in Bosnia and Herzegovina are of concern, because fluoroquinolones are recognised by WHO as critically important antibiotics in human medicine which are used for treating severe and invasive infections (World Health Organization, 2017). Therefore, we must focusing on measures to maximaly reduce their use in poultry and other farm animals. 


\section{References:-}

1. Johnson, JR., Kuskowski, MA., Menard, M., Gajewski, A., Xercavins, M., Garau, J. (2006). Similarity of human and chicken-source Escherichia coli isolates in relation to ciprofloxacin resistance status. $\mathrm{J}$ Infect Dis.;194:71-8.

2. Amundsen, D., Lindholm, C., Goyal SM, Robinson RA. (1988). Microbial pollution of well water in southeastern Minnesota. J Environ Sci Health;23:453-68.

3. Anderson, AD., Nelson, JM., Rossiter, S., Angulo, FJ. (2003). Public health consequences of usenof antimicrobial agents in food animals in the United States. Microb Drug Resist.;9:373-9.

4. Arathy, DS., Vanpee, G., Belot, G., Mathew, V., DeAllie, C., Sharma, R. (2011). Antimicrobial drug resistance in Escherichia coli isolated from commercial chicken eggs in Grenada, West Indies. West Indian Med J.;60:536.

5. Arias, C., Cortes, F., Reyes, J., Diaz, L., Vanegas, N., Rincon, S. (2005). Ciprofloxacin-Resistant E. coli (CREC) in Chicken Fecal Samples and Retail Poultry Meat in Bogotá, Colombia. 43rd Annual Meeting; Session: Bacterial Antibiotics October 7.

6. BAS EN ISO 16649-2. (2008). Horizontal method for the counting of the positive Escherichia coli glucuronidase - Part 2: Colony counting technique at $44^{\circ} \mathrm{C}$ using 5-bromo-4-chloro-3-indolyl-D-glucuronide (ISO 16649-2: 2001, IDT).

7. BAS EN ISO 6887-1. (2005). Microbiology of food and animal feeding stuffs - Preparation of test specimens, initial suspensions and decimal dilutions for microbiological tests - Part 1: General rules for the preparation of initial suspensions and decimal dilutions (EN ISO 6887-1: 1999, IDT, ISO 6887-1: 1999, IDT ).

8. Blanco, J., Blanco, M., Mora, A., Blanco, J. (1997). Prevalence of bacterial resistance to quinolones and other antimicrobials among avian Escherichia coli strains isolated from septicemic and healthy chickens in Spain. J Clin Microbiol.; / 35: / 2184/5.

9. Chiu, C.-H., Wu, T.-L., Su, L.-H., Chu, C., Chia, J.-H.,. Kuo, A.-J., Chien, M.-S., and Lin, T.-Y. (2002). The emergence in Taiwan of fluoroquinolone resistance in Salmonella enterica serotype choleraesuis. N. Engl. J. Med. 346: 413-419.

10. Clinical and Laboratory Standards Institute. (2017). Performance Standards for Antimicrobial Susceptibility Testing. 27th ed. CLSI supplement M100.Wayne, PA: Clinical and Laboratory Standards Institute.

11. Cogan, TA., Bloomfield, SF., Humphrey, T J. (1999). The effectiveness of hygiene procedures for prevention of cross-contamination from chicken carcasses in the domestic kitchen. Lett. Appl. Microbiol.; 29:354-358.

12. EFSA (European Food Safety Authority) and ECDC (European Centre for Disease Prevention and Control). (2018). The European Union summary report on antimicrobial resistance in zoonotic and indicator bacteria from humans, animals and food in 2016. EFSA Journal.;16 (2):5182, $270 \quad$ pp. https://doi.org/10.2903/j.efsa.2018.5182

13. Friedman, ND., Kaye, KS., Stout, JE., McGarry, SA., Trivette, S.L, Briggs, JP., et al. (2002). Health careassociated bloodstream infections in adults: a reason to change the accepted defnition of community-acquired infections. Ann Intern Med.137:791-7.

14. Gales, AC., Jones, RN., Kelley, GA., Sader, HS., Wilke, WW., Beac, ML., et al. (2000). Activity and spectrum of 22 antimicrobial agents tested against urinary tract infection pathogens in hospitalized patients in Latin America: Report from the second year of the SENTRY Antimicrobial Surveillance Program (1998). J Antimicrob Chemother.;45:295/303

15. Garau, J., Xercavins, M., Rodriguez-Carballeira, M., Gomez-Vera, J., Coll,I., Vidal, Llovet, D., and RuizBremon, A. (1999). Emergence and dissemination of quinolone-resistant Escherichia coli in the community. Antimicrob. Agents Chemother. 43:2736-2741.

16. Gorbach, S. (2001). Antimicrobial use in animal feed-time to stop. N. Engl.J. Med. 345:1201-1203.

17. Jensen, VF., Jakobsen, L., Emborg, H., Seyfarth, AM., Hammerum, AM. (2006). Correlation between apramycin and gentamicin use in pigs and an increase reservoir of gentamicin-resistant Escherichia coli. J Antimicrob Chemother.;58:101-7. http://dx.doi.org/10.1093/jac/ dkl201

18. Johnson, JR., Murray, AC., Gajewski, A., Sullivan, M., Snippes, P., Kuskowski, MA., Smith, KE. (2003). Isolation and molecular characterization of nalidixic acid-resistant extraintestinal pathogenic Escherichia coli from retail chicken products. Antimicrob Agents Chemother.;47:2161-8.

19. Kiranmayi, CB., Krishnaiah, N., Subhashini, N., Amaravathi, P., Maheswari, M., Ramya, P. (2011) PCR analysis of mutton and chicken samples for the presence of Shiga toxigenic E.coli. Arch Clin Microbiol.;2:2-4. Available from: [http://imedpub.com/ojs/index.php/acmicrob/article/view/272/260].

20. Levy, SB., Marshall, B. (2004). Antibacterial resistance worldwide: causes, challenges and responses. Nat Med.;10(Suppl):S122-9. http:// dx.doi.org/10.1038/nm1145 
21. Linton, A. Howe, H., K., Bennett, P. M., and Richmond, M. H. (1977). The colonization of the human gut by antibiotic resistant Escherichia coli from chickens. J. Appl. Bacteriol. 43:465-469.

22. McDonald, LC., Feng-Jui, C., Hsiu-Jung, LO., Hsiao-Chuan, Y., Po-Ling, L., Cheng-Hua H., et al. (2001). Emergence of reduced susceptibility and resistance to fluoroquinolones in Escherichia coli in Taiwan and contributions of distinct selective pressures. Antimicrob Agents Chemother.; 45: 9084-91.

23. McEwen, SA., Fedorka-Cray, P. (2002). Antimicrobial use and resistance in animals. Clin Infect Dis.; 34(Suppl 3):S93-106. http://dx.doi. org/10.1086/340246

24. Moniri, R., Dastehgoli, K. (2005). Fluoroquinolone-resistant Escherichia coli isolated from healthy broilers with previous exposure to fluoroquinolones: Is there a link? Microbial Ecology in Health and Disease.; 17: $69 / 74$

25. Reis, AC., Santos, SR., Souza, SC., Saldanha, MG., Pitanga, TN., Oliveira, RR. (2016). Ciprofloxacin resistance pattern among bacteria isolated from patients with community-acquired urinary tract infection. Rev Inst Med Trop Sao Paulo.; 58:53.

26. Smith, K. E., Besser, J. M., Hedberg, C. W., Leano, F. T., Bender, J. B., Wicklund, J. H., Johnson, B. P., Moore, K. A., Osterholm, M. T., and Team, T. I. (1999). Quinolone-resistant Campylobacter jejuni infections in Minnesota, 1992-1998. N. Engl. J. Med. 340:1525-1532.

27. Thorsteinsdottir, TR., Haraldsson, G., Fridriksdottir, V., Kristinsson, KG., Gunnarsson, E. (2010). Broiler chickens as source of fluoroquinolone-resistant Escherichia coli, Iceland. Emerg Infect Dis. Jan; 16(1): 133135. doi: $10.3201 /$ eid1601.09024.

28. World Health Organization. (2017). Critically important antimicrobials for human medicine, 5th revision. World Health Organization; Geneva,. (http://www.who.int/foodsafety/publications/antimicrobialsfifth/e/ 